\title{
Clinical efficacy and safety of apatinib combined with S-1 in advanced esophageal squamous cell carcinoma
}

\author{
Jian Zhao ${ }^{1,2}$ - Junmei Lei ${ }^{3}$ - Junyan $\mathrm{Yu}^{4} \cdot$ Chengyan Zhang ${ }^{2} \cdot$ Xuefeng Song $^{2}$ - Ninggang Zhang ${ }^{2,5}$. \\ Yusheng Wang ${ }^{2,5}$ (D) Suxiang Zhang ${ }^{2}$
}

Received: 17 September 2019 / Accepted: 9 October 2019/Published online: 24 October 2019

(C) The Author(s) 2019

\section{Summary}

Background Esophageal cancer is a very common malignant tumor in China, especially esophageal squamous cell carcinoma (ESCC), but there is currently no effective treatment for patients after first-line chemotherapy failure. Apatinib has shown promising outcomes in treatment with various solid tumors. Objectives To evaluate the clinical efficacy and safety of apatinib combined with S-1 in the treatment of advanced ESCC patients after first-line chemotherapy failure. Methods In this prospective study, fifteen patients with advanced ESCC who failed first-line chemotherapy were enrolled from Nov 2016 to Apr 2019. Patients received the combination therapy with apatinib (250-500 mg, once daily) plus S-1 (40-60 mg based on body surface area, twice daily). Primary endpoint was progression-free survival (PFS). Secondary endpoints included overall survival (OS), disease control rate (DCR) and objective response rate (ORR). Adverse events (AEs) were recorded to evaluate the safety. Results A total of 12 patients were included in the efficacy analysis. The median PFS was 6.23 months, and the median OS was 8.83 months. Two (16.67\%) patients achieved partial remission, 9 patients $(75.00 \%)$ achieved stable disease and $1(8.33 \%)$ patient achieved progressive disease. DCR and ORR was 91.67\% and 16.67\%, respectively. Most frequent AEs were hypertension, myelosuppression, weakness, hemorrhage, hand-foot syndrome, total bilirubin elevation, sick, proteinuria, oral ulcer, loss of appetite, and transaminase elevation. The most AEs were in grade I II. Conclusion The combination therapy of apatinib plus S-1 was effective and well tolerated in the treatment of advanced ESCC patients after first-line chemotherapy failure. The combination therapy has the potential to be a potent therapeutic option for advanced ESCC patients after first-line chemotherapy failure.

Keywords Esophageal squamous cell carcinoma $\cdot$ Apatinib $\cdot$ S-1 $\cdot$ Adverse effect $\cdot$ Survival

Yusheng Wang

wangyusheng1972@163.com

1 Shanxi Medical University, Taiyuan, Shanxi 030001, People's Republic of China

2 Department of Digestive, Affiliated Cancer Hospital of Shanxi Medical University, Taiyuan, Shanxi 030013, People's Republic of China

3 Department of Oncology, Jincheng General Hospital, Jincheng, Shanxi 048000, People's Republic of China

4 Department of Oncology, Affiliated Peace Hospital of Changzhi Medical College, Changzhi, Shanxi 046000, People's Republic of China

5 Capital Medical University, Beijing 100069, People's Republic of China

\section{Introduction}

Esophageal cancer is the sixth leading cause of cancer death worldwide [1]. It is also a common malignant tumor in China, especially esophageal squamous cell carcinoma (ESCC), with obvious regional distribution characteristics $[2,3]$. However, most patients were diagnosed at the advanced stage, resulting in the loss of chance to receive the surgery [4]. For early esophageal cancer, endoscopic submucosal dissection (ESD) and endoscopic mucosal resection (EMR) may be preferred [5]. For advanced patients, local radiotherapy and/or systemic chemotherapy are required. Chemotherapy can alleviate clinical symptoms, improve quality of life, and prolong survival. Currently, first-line chemotherapy for advanced esophageal cancer mainly includes fluorouracil-based or platinumcontaining regimens. However, there is no effective treatment for patients after at least first-line chemotherapy failure. 
Therefore, the novel therapeutic regimen for advanced ESCC is urgently needed.

In recent years, vascular endothelial growth factor receptor (VEGFR) has been shown to be an important anti-cancer target in the targeted therapy of solid tumors. Since 1970s, Folkman et al. has provided evidence that the growth and metastasis of solid tumors are associated with angiogenesis [6-8]. Bevacizumab is the first drug that approved by US Food and Drug Administration to inhibit tumor angiogenesis. It is actually a humanized variant of anti-VEGF antibody that specifically binds to VEGF-A to promote tumor vascular normalization [9]. VEGF exerts angiogenesis effect by binding to various transmembrane proteins and there are three primary receptors, including VEGFR-1, VEGFR-2, and VEGFR-3. Moreover, several studies have shown that ESCC growth can be inhibited by selectively inhibiting VEGFR-1 and VEGFR-2 [10-12].

Apatinib is an oral small-molecule tyrosine kinase inhibitor (TKI) that selectively binds to and inhibits VEGFR2. A retrospective study suggested that apatinib may be beneficial for patients with ESCC, the objective response rate (ORR) and disease control rate (DCR) were $24.2 \%$ and $74.2 \%$, respectively [13]. S-1 is a fourth-generation, novel, orally active fluorouracil formulation, consisting of tegafur (FT; a prodrug of 5-FU), 5-chloro-2,4-dihydroxypyridine (CDHP) and potassium oxonate (Oxo), in a molar ratio of 1:0.4:1 [14]. CDHP can maintain prolonged efficacious 5 -FU concentrations in the blood by inhibiting dihydropyrimidine dehydrogenase (DPD). Oxo can suppress the gastrointestinal toxicity of 5-FU and without affecting the antitumor activity of 5-FU [15]. At present, there is no relevant research. Our objective is to preliminarily evaluate the efficacy and safety of combination drug therapy.

Herein we present an interim analysis of a prospective study to evaluate the efficacy and safety of apatinib combined with S-1 in advanced ESCC.

\section{Materials and methods}

\section{Patients and study design}

This prospective study enrolled 15 patients with advanced ESCC who experienced at least one failure of first-line chemotherapy from Nov 2016 to Apr 2019 at Affiliated Cancer Hospital of Shanxi Medical University. The study was conducted in accordance with the Declaration of Helsinki and approved by the Ethics Committee of Affiliated Cancer Hospital of Shanxi Medical University. Written informed consent was obtained from each subject. The study was registered in Chinese Clinical Trials. gov. (ChiCTR-OIH-17012822).

Inclusion criteria were as follows: (1) patients were diagnosed with stage IV ESCC by histopathology and/or cytology;
(2) had failed first-line chemotherapy; (3) presence of objectively measurable tumor lesions; (4) had an Eastern Cooperative Oncology Group (ECOG) physical status score of $0-2$; (5) without the obvious abnormalities in heart, liver and kidney function, and without the risk of bleeding and thrombosis, and chemotherapy contraindications.

\section{Drug administration}

Apatinib was administered at an initial dose of $250 \mathrm{mg}$ once daily. If the initial dose was well tolerated after one week, the dose of apatinib was adjusted to $500 \mathrm{mg}$, once daily. S-1 was administered a dose of 40-60 mg twice daily for 4 weeks followed by a 2 weeks drug interruption. Each treatment cycle was 6 weeks. The dose of S-1 was determined based on body surface area (BSA): $40 \mathrm{mg}\left(\mathrm{BSA}<1.25 \mathrm{~m}^{2}\right), 50 \mathrm{mg}$ (BSA $\left.1.25-1.5 \mathrm{~m}^{2}\right)$, and $60 \mathrm{mg}\left(\mathrm{BSA} \geq 1.5 \mathrm{~m}^{2}\right)$. Apatinib and $\mathrm{S}-1$ were provided by Jiangsu HengRui Medicine Co., Ltd. (Lianyungang, Jiangsu, China).

\section{Efficacy and safety evaluation}

Tumor response was assessed every 6 weeks by using computed tomography (CT) and tumor markers. The primary efficacy endpoint was progression-free survival (PFS).

Tumor response was categorized as complete response (CR), partial response (PR), stable disease (SD), and progressive disease (PD) according to Response Evaluation Criteria in Solid Tumors version 1.1(RECIST v1.1) [16]. The secondary efficacy endpoints were disease control rate (DCR), objective response rate (ORR) and over survival (OS). DCR was defined as the number of patients with $\mathrm{CR}, \mathrm{PR}$, and $\mathrm{SD}$ among all patients. ORR was defined as the number of patients with the best tumor response (CR and PR) among all patients. Adverse events (AEs) were recorded to evaluate the safety. All AEs were graded according to the Common Terminology Criteria for Adverse Events (CTCAE) Version 4.0, ranging from 0 to 4.

\section{Statistical analysis}

PFS data for patients without disease progression or loss of follow-up were censored at the time of last tumor assessment. OS data for patients who survived or lost follow-up were censored at the time of last confirmed exposure. Safety assessment was analyzed in safety analysis set (SAS), which included all patients who had received at least one dose of study treatment. SPSS version 19.0 (SPSS Inc. USA) was used for all statistical analyses. Quantitative data were described using mean, standard deviation (SD), median, and interquartile range, while qualitative data were described by number or percentage. OS and PFS were estimated by using the Kaplan-Meier method. A value of $p<0.05$ was considered as statistically significant. 


\section{Results}

\section{Patients baseline}

A total of 15 patients were enrolled in present study (Table 1). All patients have experienced at least one failure of first-line chemotherapy. The present study enrolled $8(53.3 \%)$ males and $7(46.7 \%)$ females, with the median age of 68 (range,

Table 1 Patients characteristics

\begin{tabular}{|c|c|c|}
\hline & \multicolumn{2}{|l|}{$\mathrm{N}=15$} \\
\hline & $\mathrm{NO}$ & $\%$ \\
\hline \multicolumn{3}{|l|}{ Age (years) } \\
\hline Median & 68 & \\
\hline Range & $50-76$ & \\
\hline \multicolumn{3}{|l|}{ Gender } \\
\hline Male & 8 & $53.3 \%$ \\
\hline Female & 7 & $46.7 \%$ \\
\hline \multicolumn{3}{|l|}{ Location } \\
\hline Cervical esophagus & 1 & $6.7 \%$ \\
\hline Upper thoracic & 2 & $13.3 \%$ \\
\hline Middle thoracic & 4 & $26.7 \%$ \\
\hline Lower thoracic & 6 & $40.0 \%$ \\
\hline Esophagogastric junction & 0 & $0.0 \%$ \\
\hline NA & 2 & $13.3 \%$ \\
\hline \multicolumn{3}{|l|}{ Surgery } \\
\hline Yes & 6 & $40.0 \%$ \\
\hline No & 9 & $60.0 \%$ \\
\hline \multicolumn{3}{|l|}{ Differentiation } \\
\hline Poorly differentiated & 7 & $46.7 \%$ \\
\hline Moderately or poorly differentiated & 2 & $13.3 \%$ \\
\hline Moderately differentiated & 3 & $20.0 \%$ \\
\hline Middle to well differentiated & 1 & $6.7 \%$ \\
\hline Well-differentiated & 0 & $0 \%$ \\
\hline NA & 2 & $13.3 \%$ \\
\hline \multicolumn{3}{|l|}{ ECOG score } \\
\hline 1 & 8 & $53.3 \%$ \\
\hline 2 & 7 & $46.7 \%$ \\
\hline \multicolumn{3}{|l|}{ The numbers of metastases } \\
\hline$\leq 2$ & 6 & $40.0 \%$ \\
\hline$>2$ & 6 & $40.0 \%$ \\
\hline NA & 3 & $20.0 \%$ \\
\hline \multicolumn{3}{|l|}{ Previous treatment } \\
\hline First-line & 1 & $6.7 \%$ \\
\hline Second-line & 5 & $33.3 \%$ \\
\hline Third-line & 4 & $26.7 \%$ \\
\hline Fourth-line & 1 & $6.7 \%$ \\
\hline Fifth-line & 2 & $13.3 \%$ \\
\hline NA & 2 & $13.3 \%$ \\
\hline
\end{tabular}

ECOG, Eastern Cooperative Oncology Group
57-76). The majority of ESCC are located in the lower esophagus and the majority pathological subtype is poorly differentiated squamous cell carcinomas. All patients had an ECOG (Eastern Cooperative Oncology Group) performance status score of 0 or 2.

\section{Efficacy}

Among 15 eligible patients, 12 patients were included in the efficacy analysis. The reason for patients not included in the efficacy analysis were insufficient medication time in 2 cases and withdrawal from the trial because of AEs in 1 case. Among the 12 patients, none of patients achieved CR, 2 (16.67\%) patients achieved PR, 9 (75.00\%) patients achieved SD and $1(8.33 \%)$ patient achieved PD (Table 2). The DCR and ORR was $91.67 \%$ and $16.67 \%$, respectively (Table 2). In all 15 patients, the median PFS was 6.23 months $(95 \% \mathrm{CI}$, $1.68-10.78$ ), and median OS was 8.83 months (95\% CI, 3.6713.99) (Figs. 1 and 2).

\section{Safety}

The main AEs were listed in Table 3. Most AEs were grade I and II, including hematotoxicity and non-hematologic toxicity. Most of hematotoxicity were thrombocytopenia $(20.00 \%$, $3 / 15)$ and leukocyte reduction $(13.33 \%, 2 / 15)$; nonhematologic toxicity mainly manifested as hypertension $(40.00 \%, 6 / 15)$, weakness $(33.33 \%, 5 / 15)$, hemorrhage (20.00\%, 3/15), hand-foot syndrome (HFS) $(20.00 \%, 3 / 15)$, total bilirubin elevation $(13.33 \%, 2 / 15)$, sick $(13.33 \%, 2 / 15)$, proteinuria $(6.67 \%, 1 / 15)$, oral ulcer $(13.33 \%, 2 / 15)$, loss of appetite $(6.67 \%, 1 / 15)$, and transaminase elevation $(6.67 \%$, $1 / 15)$. The main grade III AEs were HFS $(6.67 \%, 1 / 15)$, proteinuria $(6.67 \%, 1 / 15)$, thrombocytopenia $(6.67 \%, 1 / 15)$ and hemorrhage $(6.67 \%, 1 / 15)$. Besides, one patient experienced grade IV total bilirubin elevation $(6.67 \%, 1 / 15)$ (Fig. 3).

\section{Discussion}

This is an interim analysis of a single arm, single institutional, prospective, exploratory clinical study, the median PFS was 6.23 months, and the combination of apatinib and S-1 was found to have a manageable AEs. From the available data, the efficacy seems to be related to surgery, gender, apatinib's dose, the numbers of metastases and previous treatment, but they are not statistically significant (Table 4).

Several studies have shown that S-1 was potentially efficacious for advanced ESCC. Fang et al. [17] have used paclitaxel combined with cisplatin (TP) and S-1 combined with cisplatin (CS) in the unresectable advanced ESCC. The results showed that these therapeutic regimens both achieved satisfactory survival results and the CS group was significantly 
Table 2 Detailed information of patients in this trial

\begin{tabular}{|c|c|c|c|c|c|c|c|c|c|}
\hline NO. & $\begin{array}{l}\text { Enter the } \\
\text { trail }\end{array}$ & $\begin{array}{l}\text { Withdraw from the } \\
\text { trail }\end{array}$ & The reason & $\begin{array}{l}\text { Time of } \\
\text { Death }\end{array}$ & $\begin{array}{l}\text { Previous } \\
\text { treatment }\end{array}$ & Dose & $\begin{array}{l}\text { Optimal } \\
\text { efficacy }\end{array}$ & PFS(month) & OS(month) \\
\hline 1 & 2016-11-09 & $2017-08-27$ & NA & 2017-08-27 & NA & NA & SD & 9.70 & 9.70 \\
\hline 2 & $2.17-03-23$ & $2017-12-23$ & Death & $2017-12-23$ & Fifth-line & $500 \mathrm{mg}$ & $\mathrm{SD}$ & 8.83 & 8.83 \\
\hline 3 & 2017-06-12 & 2018-04-07 & Death & 2018-04-07 & Third-line & $500 \mathrm{mg}$ & PR & 9.97 & 9.97 \\
\hline 4 & 2017-10-11 & $2017-12-25$ & Progress & 2018-01-01 & Second-line & $500 \mathrm{mg}$ & PR & 2.50 & 2.73 \\
\hline 5 & $2017-10-15$ & 2018-03-27 & Death & 2018-03-27 & Third-line & $250 \mathrm{mg}$ & $\mathrm{SD}$ & 5.43 & 5.43 \\
\hline 6 & 2017-11-29 & 2017-12-07 & $\begin{array}{l}\text { Bleeding / } \\
\text { perforation }\end{array}$ & $2017-12-30$ & NA & $250 \mathrm{mg}$ & NA & 0.27 & 1.03 \\
\hline 7 & 2018-01-05 & 2018-07-08 & NA & NA & Fifth-line & $500 \mathrm{mg}$ & SD & 6.13 & 6.13 \\
\hline 8 & 2018-01-17 & 2019-01-31 & Death & 2019-01-31 & Third-line & $500 \mathrm{mg}$ & SD & 12.63 & 12.63 \\
\hline 9 & 2018-02-05 & 2018-04-25 & NA & NA & Second-line & $250 \mathrm{mg}$ & SD & 2.63 & 2.63 \\
\hline 10 & 2018-04-11 & 2018-05-27 & Poor compliance & 2018-09-17 & Second-line & NA & SD & 1.53 & 5.30 \\
\hline 11 & 2018-04-23 & 2018-08-13 & Death & 2018-08-28 & Third-line & $250 \mathrm{mg}$ & $\mathrm{SD}$ & 3.73 & 4.23 \\
\hline 12 & 2018-06-22 & $2018-12-26$ & Anemia & 2019-03-27 & First-line & $250 \mathrm{mg}$ & $\mathrm{SD}$ & 6.23 & 9.27 \\
\hline 13 & 2018-12-05 & 2019-01-14 & Progress & NA & Second-line & $375 \mathrm{mg}$ & $\mathrm{PD}$ & 1.33 & 4.87 \\
\hline 14 & 2019-03-27 & & & & Forth-line & $250 \mathrm{mg}$ & NA & & \\
\hline 15 & 2019-04-03 & & & & Second-line & $250 \mathrm{mg}$ & NA & & \\
\hline
\end{tabular}

$S D$, stable disease; $P D$, progressive disease; $P R$, partial response; $N A$, no answer; $P F S$, progression-free survival; $O S$, overall survival

better than the TP group in terms of compliance, hospital stay, and toxicity. In general, targeted drugs have better safety and tolerability profile compared with chemotherapy drugs.

Multiple targeted drugs have been applied in the treatment of ESCC with first-line chemotherapy failure. Previously, a randomized phase III clinical trial of gefitinib has confirmed its efficacy in esophageal cancer [18]. Actually, gefitinib is a selective epidermal growth factor receptor tyrosine kinase inhibitor (EGFR-TKI), however its efficacy is limited to the esophageal cancer with EGFR gene-sensitive mutations. Moreover, Lorenzen et al. have compared the efficacy of cetuximab combined with cisplatin+5-FU (CET-CF) and cisplatin+5-FU (CF) in the treatment of advanced metastatic

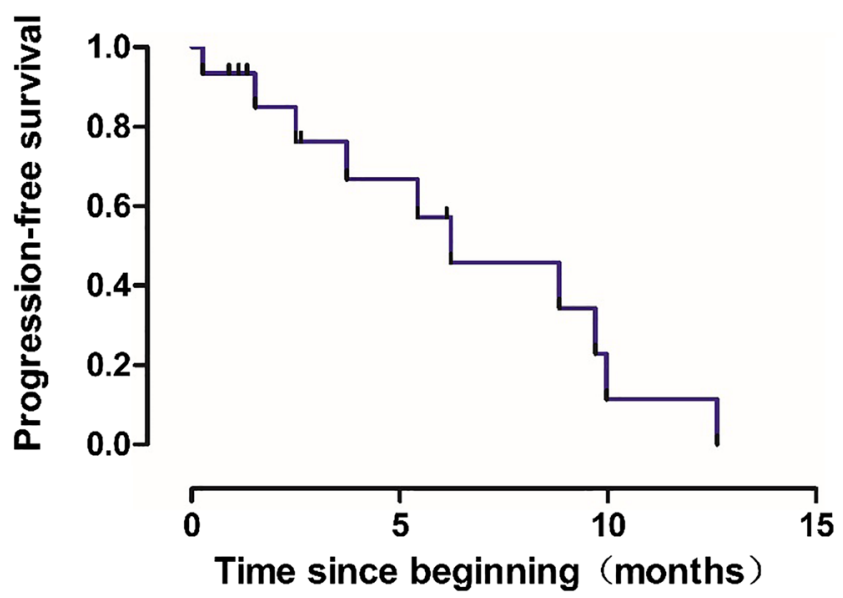

Fig. 1 Kaplan-Meier analysis of progression-free survival in patients treated with apatinib combined with S-1 $(n=15)$ mPFS: 6.23 months $(95 \%$ CI, 1.68-10.78)
ESCC [19], but without clear conclusion. Sunitinib targets VEGFR1-3, PDGFR $\alpha$, PDGFR $\beta$ and c-kit [20]. A phase II study evaluated adjuvant sunitinib following chemoradiotherapy and surgery for locally advanced esophageal cancer. In this study, median survival was 26 months. But all patients were poorly tolerated, and these results were not stratified according to histology [12].

Apatinib mesylate is a small molecule anti-angiogenic targeted drug independently developed by Jiangsu HengRui Medicine Co., Ltd., which could selectively inhibit the activity of VEGFR-2 tyrosine kinase. VEGF could bind to its receptor, and thereby potently inhibit tumor angiogenesis to exert its anti-tumor effects. Usually, malignant tumors are rich in blood

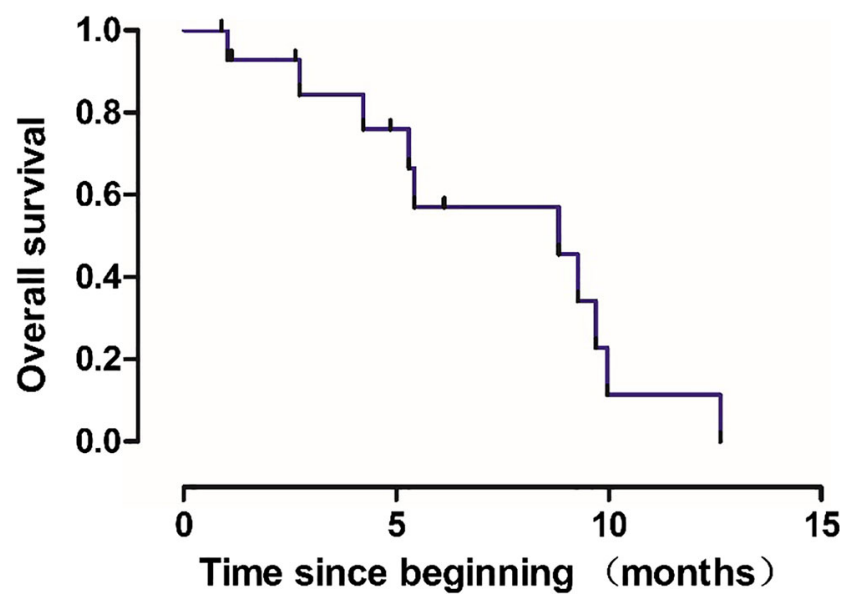

Fig. 2 Kaplan-Meier analysis of overall survival in patients treated apatinib combined with S-1 $(\mathrm{n}=15)$. mOS: 8.83 months $(95 \% \mathrm{CI}$, 3.67-13.99) 
Table 3 Adverse events

\begin{tabular}{|c|c|c|c|c|c|c|}
\hline \multirow[t]{2}{*}{ Adverse events } & \multicolumn{4}{|c|}{ Grade } & \multirow[t]{2}{*}{ Incidence } & \multirow[t]{2}{*}{ Main grade 3-4 toxicities } \\
\hline & I & II & III & IV & & \\
\hline Hypertension & 3 & 3 & & & $40.00 \%$ & $0.00 \%$ \\
\hline Thrombocytopenia & 2 & & 1 & & $20.00 \%$ & $6.67 \%$ \\
\hline Weakness & 2 & 3 & & & $33.33 \%$ & $0.00 \%$ \\
\hline Hemorrhage & & 2 & 1 & & $20.00 \%$ & $6.67 \%$ \\
\hline Leukocyte reduction & 1 & 1 & & & $13.33 \%$ & $0.00 \%$ \\
\hline Hand-foot syndrome & & 2 & 1 & & $20.00 \%$ & $6.67 \%$ \\
\hline Total bilirubin elevation & 1 & & & 1 & $13.33 \%$ & $6.67 \%$ \\
\hline Sick & 2 & & & & $13.33 \%$ & $0.00 \%$ \\
\hline Oral ulcer & 2 & & & & $13.33 \%$ & $0.00 \%$ \\
\hline Proteinuria & & & 1 & & $6.67 \%$ & $6.67 \%$ \\
\hline Loss of appetite & 1 & & & & $6.67 \%$ & $0.00 \%$ \\
\hline Transaminase elevation & 1 & & & & $6.67 \%$ & $0.00 \%$ \\
\hline
\end{tabular}

vessels, which are the basis of tumor growth and metastasis. The blood vessels could provide nutrients to tumor tissues continuously, and also transport tumor cells to other parts of the body. Given that most solid tumors have a rich blood supply, and thus apatinib is theoretically effective for ESCC. Since apatinib was marketed in 2014, it has been proven to be effective in various cancer, such as gastric cancer [21], liver cancer [22], breast cancer [23], lung cancer [24], ovarian cancer [25], and thyroid cancer [26]. In the current study, the application of apatinib in upper digestive tract tumors mainly focused on the treatment of esophageal adenocarcinoma, gastro-oesophageal junction cancer and gastric cancer [21]. At present, although the efficacy of apatinib monotherapy in advanced ESCC has been confirmed in China, its efficacy is
Fig. 3 Hand-foot syndrome. These pictures were taken from three patients with hand-foot syndrome after apatinib combined with S-1, and they are tolerable after symptomatic treatment. (The consent and authorization have been obtained)
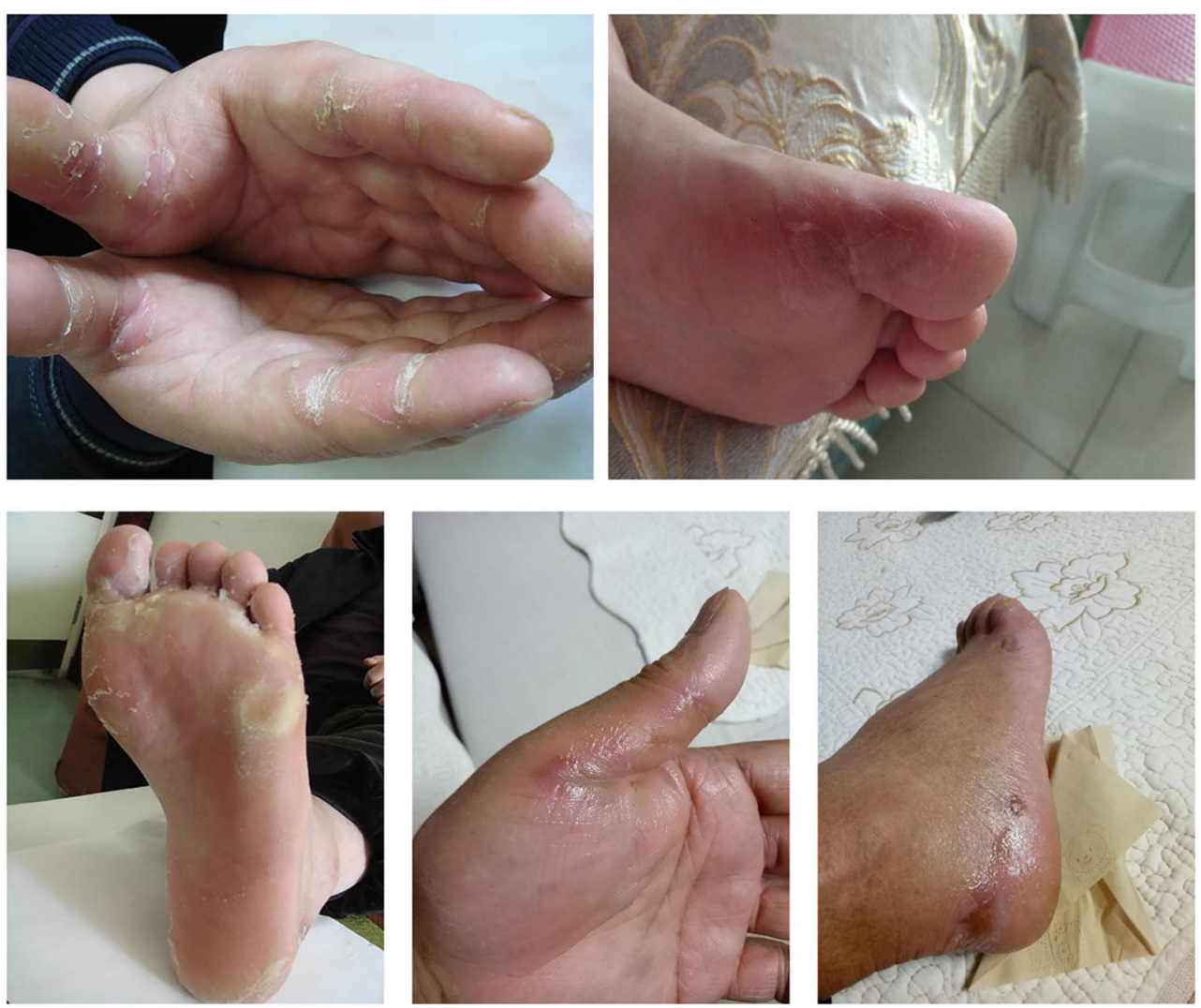
Table 4 Univariate analysis of the current population $(n=15)$

\begin{tabular}{|c|c|c|c|c|c|c|}
\hline & PFS & $95 \% \mathrm{CI}$ & $\mathrm{P}$ & OS & $95 \% \mathrm{CI}$ & $\mathrm{P}$ \\
\hline \multicolumn{7}{|l|}{ Surgery } \\
\hline $\begin{array}{l}\text { Yes } \\
\text { No }\end{array}$ & $\begin{array}{l}6.13 \\
8.83\end{array}$ & $\begin{array}{l}0.70-11.56 \\
2.10-15.57\end{array}$ & 0.491 & $\begin{array}{l}6.13 \\
8.83\end{array}$ & $\begin{array}{l}1.04-11.22 \\
4.13-13.52\end{array}$ & 0.605 \\
\hline \multicolumn{7}{|l|}{ Gender } \\
\hline $\begin{array}{l}\text { Male } \\
\text { Female }\end{array}$ & $\begin{array}{l}5.43 \\
6.23\end{array}$ & $\begin{array}{l}0-12.83 \\
1.23-11.23\end{array}$ & 0.849 & $\begin{array}{l}5.43 \\
8.83\end{array}$ & $\begin{array}{l}5.11-5.75 \\
3.89-13.77\end{array}$ & 0.962 \\
\hline \multicolumn{7}{|l|}{ Apatinib's dose } \\
\hline $\begin{array}{l}500 \mathrm{mg} \\
<500 \mathrm{mg}\end{array}$ & $\begin{array}{l}8.83 \\
5.43\end{array}$ & $\begin{array}{l}3.03-14.63 \\
2.67-8.19\end{array}$ & 0.303 & $\begin{array}{l}8.83 \\
5.43\end{array}$ & $\begin{array}{l}3.03-14.63 \\
3.65-7.21\end{array}$ & 0.448 \\
\hline \multicolumn{7}{|c|}{ The numbers of metastases } \\
\hline $\begin{array}{l}\leq 2 \\
>2\end{array}$ & $\begin{array}{l}8.83 \\
6.13\end{array}$ & $\begin{array}{l}3.58-14.08 \\
4.63-7.63\end{array}$ & 0.777 & $\begin{array}{l}4.23 \\
6.13\end{array}$ & $\begin{array}{l}0-10.21 \\
4.63-7.63\end{array}$ & 0.966 \\
\hline \multicolumn{7}{|l|}{ Previous treatment } \\
\hline $\begin{array}{l}\text { Second-line } \\
\text { Beyond second-line }\end{array}$ & $\begin{array}{l}2.50 \\
6.13\end{array}$ & $\begin{array}{l}0-5.57 \\
2.05-10.21\end{array}$ & 0.392 & $\begin{array}{l}5.30 \\
6.13\end{array}$ & $\begin{array}{l}1.45-9.15 \\
2.05-10.21\end{array}$ & 0.629 \\
\hline
\end{tabular}

still limited. In this study, the most common AEs occurred in patients who received apatinib combined with S-1 was hypertension and myelosuppression. However, most AEs were mild in severity and resolved soon with treatment interruption and symptomatic treatment. Additionally, only a fewer patients experienced grade 3 or 4 toxicity or serious AEs and no patients experienced irreversible toxicity. Notably, apatinib and S-1 drugs are oral medications that can improve patient's quality of life and treatment adherence.

In conclusion, the combination therapy of apatinib plus S-1 was effective and well tolerated in the treatment of advanced ESCC patients after first-line chemotherapy failure. The combination therapy has the potential to be a potent therapeutic option for advanced ESCC patients after first-line chemotherapy failure. However, due to the relative small sample size, further studies with a larger number of samples are required to verify our findings.

Funding The work was supported by 2016 China Anti-Cancer Association-Hengrui Medicine Innovative Medicine Clinical Research Fund Project No.26 (CACA-CORP-143-026).

\section{Compliance with ethical standards}

Conflict of interest Jian Zhao declares that he has no conflict of interest. Junmei Lei declares that she has no conflict of interest. Junyan Yu declares that he has no conflict of interest. Chengyan Zhang declares that she has no conflict of interest. Xuefeng Song declares that she has no conflict of interest. Ninggang Zhang declares that he has no conflict of interest. Yusheng Wang declares that she has no conflict of interest. Suxiang Zhang declares that she has no conflict of interest.

Ethical approval All procedures performed in studies involving human participants were in accordance with the ethical standards of the institutional and/or national research committee and with the 1964 Helsinki declaration and its later amendments or comparable ethical standards.
Informed consent Informed consent was obtained from all individual participants included in the study.

Open Access This article is distributed under the terms of the Creative Commons Attribution 4.0 International License (http:// creativecommons.org/licenses/by/4.0/), which permits unrestricted use, distribution, and reproduction in any medium, provided you give appropriate credit to the original author(s) and the source, provide a link to the Creative Commons license, and indicate if changes were made.

\section{References}

1. Ferlay J, Soerjomataram I, Dikshit R, Eser S, Mathers C, Rebelo M, Parkin DM, Forman D, Bray F (2015) Cancer incidence and mortality worldwide: sources, methods and major patterns in GLOBOCAN 2012. Int J Cancer 136(5):E359-E386. https://doi. org/10.1002/ijc.29210

2. Torre LA, Bray F, Siegel RL, Ferlay J, Lortet-Tieulent J, Jemal A (2015) Global cancer statistics, 2012. CA Cancer J Clin 65(2):87108. https://doi.org/10.3322/caac.21262

3. Chen W, Zheng R, Baade PD, Zhang S, Zeng H, Bray F, Jemal A, Yu XQ, He J (2016) Cancer statistics in China, 2015. CA Cancer J Clin 66(2):115-132. https://doi.org/10.3322/caac.21338

4. Abnet CC, Arnold M, Wei WQ (2018) Epidemiology of esophageal squamous cell carcinoma. Gastroenterology 154(2):360-373. https://doi.org/10.1053/j.gastro.2017.08.023

5. Malik S, Sharma G, Sanaka MR, Thota PN (2018) Role of endoscopic therapy in early esophageal cancer. World J Gastroenterol 24(35):3965-3973. https://doi.org/10.3748/wjg.v24.i35.3965

6. Folkman J, Merler E, Abernathy C, Williams G (1971) Isolation of a tumor factor responsible for angiogenesis. J Exp Med 133(2): 275-288. https://doi.org/10.1084/jem.133.2.275

7. Rosenthal RA, Megyesi JF, Henzel WJ, Ferrara N, Folkman J (1990) Conditioned medium from mouse sarcoma 180 cells contains vascular endothelial growth factor. Growth Factors 4(1):5359. https://doi.org/10.3109/08977199009011010 
8. Folkman J (1995) Angiogenesis in cancer, vascular, rheumatoid and other disease. Nat Med 1(1):27-31

9. Ferrara N, Hillan KJ, Gerber H-P, Novotny W (2004) Discovery and development of bevacizumab, an anti-VEGF antibody for treating cancer. Nat Rev Drug Discov 3(5):391-400. https://doi. org/10.1038/nrd1381

10. Janjigian YY, Vakiani E, Ku GY, Herrera JM, Tang LH, Bouvier N, Viale A, Socci ND, Capanu M, Berger M, Ilson DH (2015) Phase II trial of Sorafenib in patients with chemotherapy refractory metastatic esophageal and Gastroesophageal (GE) junction Cancer. PLoS One 10(8):e0134731. https://doi.org/10.1371/journal.pone. 0134731

11. Xu WW, Li B, Lam AK, Tsao SW, Law SY, Chan KW, Yuan QJ, Cheung AL (2015) Targeting VEGFR1- and VEGFR2-expressing non-tumor cells is essential for esophageal cancer therapy. Oncotarget 6(3):1790-1805. https://doi.org/10.18632/oncotarget. 2781

12. Horgan AM, Darling G, Wong R, Guindi M, Liu G, Jonker DJ, Lister J, Xu W, MacKay HM, Dinniwell R, Kim J, Pierre A, Shargall Y, Asmis TR, Agboola O, Seely AJ, Ringash J, Wells J, Marginean EC, Haider M, Knox JJ (2016) Adjuvant sunitinib following chemoradiotherapy and surgery for locally advanced esophageal cancer: a phase II trial. Dis Esophagus 29(8):1152-1158. https://doi.org/10.1111/dote.12444

13. Jianqiang L, Lifen W (2017) Efficacy and safety of apatinib treatment for advanced esophageal squamous cell carcinoma. Onco Targets Ther 10:3965-3969. https://doi.org/10.2147/OTT.S132756

14. Shirasaka T, Shimamato Y, Ohshimo H, Yamaguchi M, Kato T, Yonekura K, Fukushima M (1996) Development of a novel form of an oral 5-fluorouracil derivative (S-1) directed to the potentiation of the tumor selective cytotoxicity of 5-fluorouracil by two biochemical modulators. Anti-Cancer Drugs 7(5):548-557

15. Shirasaka T, Shimamoto Y, Fukushima M (1993) Inhibition by oxonic acid of gastrointestinal toxicity of 5-fluorouracil without loss of its antitumor activity in rats. Cancer Res 53(17):4004-4009

16. Watanabe H, Okada M, Kaji Y, Satouchi M, Sato Y, Yamabe Y, Onaya H, Endo M, Sone M, Arai Y (2009) New response evaluation criteria in solid tumours-revised RECIST guideline (version 1.1). Gan To Kagaku Ryoho 36(13):2495-2501

17. Fang M, Song T, Liang X, Lv S, Li J, Xu H, Luo L, Jia Y (2017) Comparative study of cisplatin-based definitive concurrent chemoradiotherapy with S-1 versus paclitaxel for unresectable locally advanced esophageal squamous cell carcinoma. Oncotarget 8(23): 37080-37090. https://doi.org/10.18632/oncotarget.16180

18. Dutton SJ, Ferry DR, Blazeby JM, Abbas H, Dahle-Smith A, Mansoor W, Thompson J, Harrison M, Chatterjee A, Falk S, Garcia-Alonso A, Fyfe DW, Hubner RA, Gamble T, Peachey L, Davoudianfar M, Pearson SR, Julier P, Jankowski J, Kerr R, Petty RD (2014) Gefitinib for oesophageal cancer progressing after chemotherapy (COG): a phase 3 , multicentre, double-blind, placebo- controlled randomised trial. Lancet Oncol 15(8):894-904. https:// doi.org/10.1016/s1470-2045(14)70024-5

19. Lorenzen S, Schuster T, Porschen R, Al-Batran SE, Hofheinz R, Thuss-Patience P, Moehler M, Grabowski P, Arnold D, Greten T, Muller L, Rothling N, Peschel C, Langer R, Lordick F (2009) Cetuximab plus cisplatin-5-fluorouracil versus cisplatin-5fluorouracil alone in first-line metastatic squamous cell carcinoma of the esophagus: a randomized phase II study of the Arbeitsgemeinschaft Internistische Onkologie. Ann Oncol 20 (10):1667-1673. https://doi.org/10.1093/annonc/mdp069

20. Morabito A, De Maio E, Di Maio M, Normanno N, Perrone F (2006) Tyrosine kinase inhibitors of vascular endothelial growth factor receptors in clinical trials: current status and future directions. Oncologist 11(7):753-764. https://doi.org/10.1634/theoncologist. 11-7-753

21. Li J, Qin S, Xu J, Guo W, Xiong J, Bai Y, Sun G, Yang Y, Wang L, Xu N, Cheng Y, Wang Z, Zheng L, Tao M, Zhu X, Ji D, Liu X, Yu H (2013) Apatinib for chemotherapy-refractory advanced metastatic gastric cancer: results from a randomized, placebo-controlled, parallel-arm, phase II trial. Journal of clinical oncology : official journal of the American Society of Clinical Oncology 31(26): 3219-3225. https://doi.org/10.1200/jco.2013.48.8585

22. Liang Q, Kong L, Du Y, Zhu X, Tian J (2019) Antitumorigenic and antiangiogenic efficacy of apatinib in liver cancer evaluated by multimodality molecular imaging. Exp Mol Med 51(7):76. https:// doi.org/10.1038/s12276-019-0274-7

23. Li YH, Zhou Y, Wang YW, Tong L, Jiang RX, Xiao L, Zhang GJ, Xing SS, Qian F, Feng JQ, Zhao YL, Wang JG, Wang XH (2018) Comparison of apatinib and capecitabine (Xeloda) with capecitabine (Xeloda) in advanced triple-negative breast cancer as third-line therapy: a retrospective study. Medicine 97(36):e12222. https://doi. org $/ 10.1097 / \mathrm{md} .0000000000012222$

24. Luo H, Zhang L, Yang B, Feng Y, Xiong Y, Zhang S, Li X, Qian C, Dong W, Dai N (2019) A randomized phase 2 trial of apatinib vs observation as maintenance treatment following first-line induction chemotherapy in extensive- stage small cell lung cancer. Investig New Drugs. https://doi.org/10.1007/s10637-019-00828-x

25. Lan CY, Wang Y, Xiong Y, Li JD, Shen JX, Li YF, Zheng M, Zhang YN, Feng YL, Liu Q, Huang HQ, Huang X (2018) Apatinib combined with oral etoposide in patients with platinum-resistant or platinum-refractory ovarian cancer (AEROC): a phase 2, singlearm, prospective study. Lancet Oncol 19(9):1239-1246. https:// doi.org/10.1016/s1470-2045(18)30349-8

26. Kan C, Yun G, Fei S, Guangqiang C, Jiandong B (2018) Apatinibtreated advanced medullary thyroid carcinoma: a case report. Onco Targets Ther 11:459-463. https://doi.org/10.2147/OTT.S142598

Publisher's note Springer Nature remains neutral with regard to jurisdictional claims in published maps and institutional affiliations. 